\title{
The Difference of Brain Activities of Musical Listeners
}

\author{
Indra K. Wardani \\ Music Department of Indonesia Institute of the Arts \\ Indonesia Institute of the Arts \\ Yogyakarta, Indonesia \\ Email: indrakwardani@gmail.com
}

\author{
Djohan \\ Graduate School of Indonesia Institute of the Arts \\ Indonesia Institute of the Arts \\ Yogyakarta, Indonesia \\ Email: djohan.djohan@yahoo.com
}

\author{
Phakkharawat Sittiprapaporn \\ Brain Science and Engineering Innovation Research Unit \\ School of Anti-Aging and Regenerative Medicine \\ Mae Fah Luang University, Bangkok, Thailand \\ Email: wichian.sit@mfu.ac.th
}

\begin{abstract}
Rapid development of music research lead into many interdisciplinary topics. These studies evoke music's integration to many subjects, such as neuroscience. In neuroscience, music is being studied related to either its effect on cognitive process or cognitive process behind it. Previous researches suggested the difference between musicians and nonmusicians in terms of brain structure and brain activity. Instead of differentiate brain activity between musician and nonmusician, this present study aims to explain the different brain activity between two musical listeners regarding to their musical experience. Using EEG technique in experimental approach toward Piano students and Karawitan students $(\mathrm{N}=40)$, this study shows higher brain activity in listening to familiar music for both piano and Karawitan students. Moreover, the dominant brain activity happened in temporal lobe when subject listened to familiar music and frontal lobe when subject listened to unfamiliar music.
\end{abstract}

Keywords-Music; EEG; Brain Activity; Piano; Karawitan

\section{INTRODUCTION}

Research of music and cognition has developed rapidly since the first it was done. Neuroscience as one of discipline focusing in cognition had examined music and its cognition process for years. Not only has it tried to explain the mechanism lies behind perception and reception of music, this discipline also tries to understand the effect of particular music (or musical activity) towards brain structurally and functionally. Many researches had been done in order to understand the effect generated by particular music activity toward brain functioning. In their research, Slumming et al. [1] explained how musical training is beneficial to enhance cognitive performance through altering brain function. Using visuospatial task applied to orchestral musicians and nonmusicians subject, Slumming tried to provide evidence on how complexity in musical training done by orchestral musicians are able to affect the activation of Broca's area during test that enhanced their performance. By comparing professional musicians, amateur musicians, and non-musicians, Gaser and

\footnotetext{
* Corresponding author: Prof. Djohan, Graduate School of Indonesia Institute
} of the Arts, Jogjakarta, Indonesia; Email: djohan.djohan@yahoo.com
Schlaug [2] explain how the structure of brain are different between those subjects. Through a morphometric study, they displayed and explained the difference of gray matter in mentioned subjects. Regarding to this result they assumed a relative contribution of long-term musical practice be done by both amateur and professional musicians as the main cause.

Another study by Patston [3] shows the different cognitive performance between expert musicians and non-musicians in terms of language and visuospatial processing. An experiment required the subjects to do language and visuospatial task with an inference of background music showed how expert musicians tent to have a decreased language task performance when a background music was played during task. Meanwhile, non-musicians tent to have a stabile task result with or without background music inference. It shows that in certain cases, music and language function are somehow independent in expert musicians, functionally.

Studies mentioned above were comparison of musicians and non-musicians where the musical experience became an important aspect as a prior conditioning to differentiate subject. Main argumentation of this assumption is based on notion that involvement of a long-time musical training and certain skill acquirement experienced by subjects enable them to have different cognitive process. Musicians go through complex rehearsal processes including physical and mental operation to construe musical notation as a visual information and alter it as motoric responses, to remember musical phrase, to do musical improvisation, and to identify a note without any referential note [5]. All of those complexities in music rehearsal were considered as brain stimuli to train its function and enhance its performance as well as develop its perception.

In terms of musical experience and perception, Ian Cross [4] explained it through a cultural difference approach. Cross gave an example of Andean music from North Potosi, Bolivia. This is a music accompanying dance where the dancer's foot falls in a certain beat of the music constantly. When he asked western listeners to listen to this music and clapped, their claps was quite different from dancer's footfalls. Cross argued this 
was caused because the western listeners 'learned' to clap in a certain way therefore they would think the dancer's foot falls in the 'offbeat'. Cross' explanation gave us insight on how the musical learning as musical experience of western listeners differentiate their way perceive a certain musical stimuli from the dancers. This insight is in line with the study by Morrison [6] and Stevens [7] that showed how different musical practices lead into different music perception and cognition in terms of musical structures. Further, Tierney et al. [8] explain the role of early musical experience in supporting auditory sequence memory among musicians. In a study employed musicians, gymnasts, video game players, and psychology students, they applied memory task on audio, visual, and audiovisual stimuli. The results showed insignificant difference on visual or audio-visual task but significant difference on audio task where musicians scored higher.

All research mentioned employed musicians and nonmusicians as the primary subject to distinguish musical experience in terms of 'had received' and 'had not received' musical teaching. It is quite clear to create such distinction between subject and to hypotheses the possible difference occurred. After all, Instead of examined brain activity difference between musicians and non-musicians, the present research aimed to describe brain activity between two musicians. The thing that differentiate our subjects is that one of them were studying western music and the other one were studying Karawitan, traditional Javanese music. Through this research we'd like to understand the possibilities of brain activity difference between those two.

\section{MATERIALS AND METHODS}

\section{A. Participants}

Twenty piano students and twenty Karawitan students were employed to be involved in this research. All participants had been explained and had approved about the applied procedure. Both piano and Karawitan students employed here should actively receive music (piano or Karawitan) practical lesson for consecutive three years. It was to make sure that each student in both groups have more or less same musical experience in terms of duration. Furthermore, we made sure that every piano students were able to play Mozart Piano Sonata in C Major and every Karawitan students were able to play Gendhing Lancaran since those two works were our main audio stimuli.

\section{B. Auditori Stimuli}

The stimuli of this experiments were two musical excerpts from Mozart's Piano Sonata in C major and Gendhing Lancaran. These two works were chosen under the consideration of the most popular and familiar works for mentioned piano students and Karawitan students. This audio stimuli was played from a MP3 player and the subject listened to this stimuli through an earphone. These two excerpts were divided into two different mp3 files in which they would not played subsequently without our permission.

\section{Data Collection}

Research on brain activity mostly uses brain imaging technique with EEG [6-7], MEG, or fMRI [3,8-9]. To collect the data of brainwave activity, this experiment used a neuroheadset named Emotiv Epoc. This is a brain-computer interface hardware with EEG concept that is design to record a real time brainwave. It is connected to a computer through a Bluetooth connection. Emotiv Epoc has 14 channels (and two referential channels) that is based on 10-20 montage system positioning. The electrode are flexible to be used in many sizes of subject's head without alter the ratio of its position. This hardware is equipped with TestBench, a software to obtain the raw data file from brainwave activity collected by Emotiv Epoc.

\section{Procedure}

Preparation of data collector is one of the most important thing in data collecting. In order to minimalize deviation caused by the equipment, Bluetooth connection between Emotiv Epoc and the computer should be in a good status as well as the battery status of the device since low battery power could lead into bad data recording. After all electrodes are well-connected with subject's scalp (by checking the status in the computer) the subjects will be informed the do's and don'ts during experiment. Beside suggesting the subjects to stay relaxed and calmed during the listening activity, important points were instructed as follows: (1) try not to move your body or body part (it is an artifact prevention of the data), (2) try not to blink or move your eyes (eye blink and movement will cause noise in the data), and (3) try to keep your eyes open during listening activity (closed eye will lead to high alpha activity in the EEG). The ready subjects subsequently listened to Mozart's Piano Sonata for 1 minute and rested for few minutes before listened to Gendhing Lancaran for another 1 minute. This study only took the brainwave activity of first minute listening to avoid an unwanted familiarity toward mentioned excerpt and to avoid subject concentration loss.

\section{E. Data Analysis}

The data collected from previous activity explained was a raw data that need to be converted and reduced. TestBench generate .edf file from brainwave recording that is need to be converted into .csv. This file is compatible for Microsoft Excel where we reduced unnecessary table and make sure that the data will be compatible to be processed further in SLORETA, a freeware developed by Pascual-Marqui to compute images of electrical neuronal activity from EEG and MEG [10]. The version we used was 20081104 that is only for EEG. This software provide an image and numerical value of seven brainwaves; delta, theta, alpha, beta-1, beta-2, beta-3, and gamma. The brainwave activity was defined in a numerical value that enable us to compare the most dominant brainwave between those all. In terms of visual result, this software able to provide a two-dimension, five views three-dimension, and six views three-dimension images. The sLORETA also provided a detailed label containing location of brainwave occurred in brain region. Since this experiment focused in comparing the most dominant brainwave occurred during listening activity 
and its particular location in brain region, this software is enough to accommodate data analyses.

\section{RESULTS}

TABLE I. Piano Students’ BANDWidth VALUE On Piano SonAta

\begin{tabular}{|l|c|c|c|c|c|c|c|}
\hline Subject & $\mathrm{d}$ & $\Theta$ & $\alpha$ & $\beta 1$ & $\beta 2$ & $\beta 3$ & $\gamma$ \\
\hline Group A & 2.714 & 3.355 & 1.454 & 1.270 & 2.986 & 4.118 & 3.895 \\
\hline
\end{tabular}

TABLE II. KARAWITAN StUdENTS' BANDWIDTH VALUE ON GENDHING

\begin{tabular}{|l|c|c|c|c|c|c|c|}
\hline Subject & $d$ & $\Theta$ & $\alpha$ & $\beta 1$ & $\beta 2$ & $\beta 3$ & $\gamma$ \\
\hline Group B & 2.529 & 2.580 & 9.705 & 5.100 & 1.381 & 1.381 & 3.093 \\
\hline
\end{tabular}

The above tables reveal bandwidth value of Piano Students and Karawitan Students when listening to Piano Sonata. The bold number indicates the most dominant brainwave occurred during listening activity: beta-3 for Piano Students and alpha for Karawitan Students. Following, the 3D views and detailed location of those two dominant brainwave will be displayed.

According to Fig. 1 and Fig.2, they reveal the dominant brainwave of Piano Students when listening to Piano Sonata is beta-3 and located in Temporal Lobe while the dominant brainwave of Karawitan Student when listening to Gendhing Lancaran is alpha and located in Frontal Lobe. Following is the bandwidth value of subject when listening to Gendhing Lancaran.

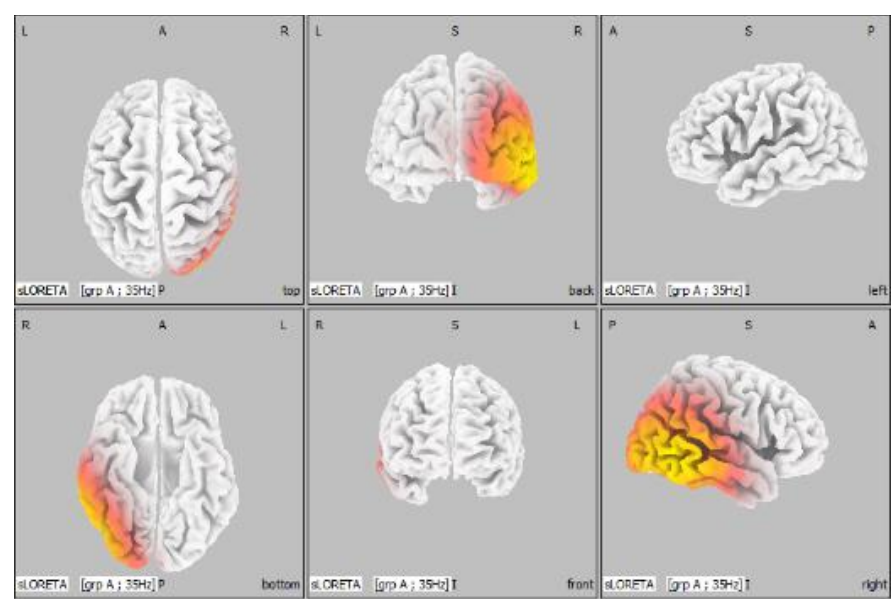

Fig. 1. Dominant brainwave of Karawitan students while listening to Gendhing Lancaran. The source generator of Beta brainwaves at Middle Temporal Gyrus - Temporal Lobe (Brodmann area 21; $\mathrm{X}=65, \mathrm{Y}=-55, \mathrm{Z}=0$; MNI coords; Best Match at $5 \mathrm{~mm} ; 4.12 \mu \mathrm{V}$ )

TABLE III. PiAno STUDENTS’ BANDWIDTH VALUE ON GENDHING LANCARAN

\begin{tabular}{|c|c|c|c|c|c|c|c|}
\hline Subject & $d$ & $\Theta$ & $\alpha$ & $\beta 1$ & $\beta 2$ & $\beta 3$ & $\gamma$ \\
\hline Grup A & 7.061 & 5.328 & 1.895 & 1.183 & 5.761 & 6.159 & 1.031 \\
\hline
\end{tabular}

TABLE IV. KARAWITAN STUDENTS’ BANDWIDTH VALUE ON GENDHING LANCARAN

\begin{tabular}{|c|c|c|c|c|c|c|c|}
\hline Subject & $d$ & $\Theta$ & $\alpha$ & $\beta 1$ & $\beta 2$ & $\beta 3$ & $\gamma$ \\
\hline Grup B & 5.289 & 7.624 & 2.969 & 1.624 & 5.518 & 1.369 & 7.259 \\
\hline
\end{tabular}

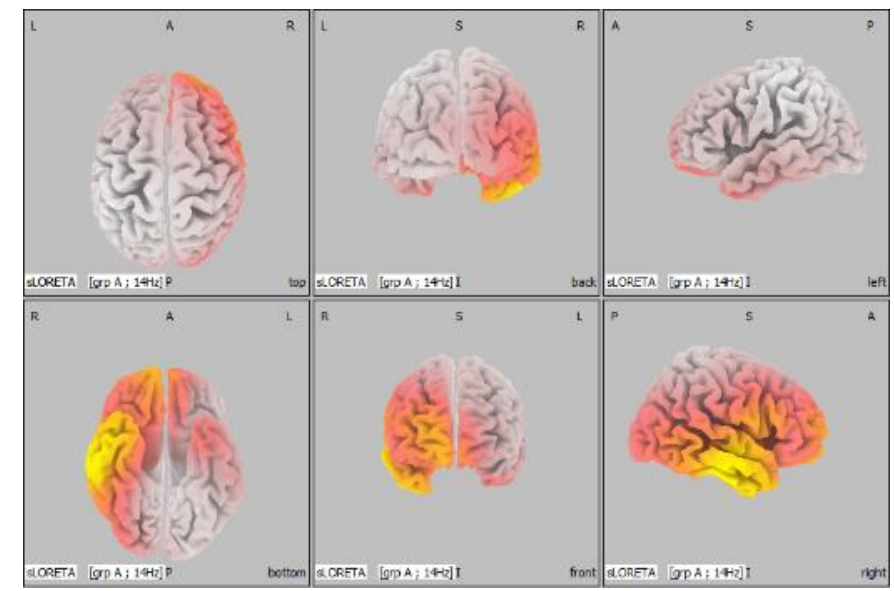

Fig. 2. Dominant brainwave of Karawitan students while listening to Piano Sonata. The source generator of Alpha brainwaves at Superior Frontal Gyrus Frontal Lobe (Brodmann area 10; $\mathrm{X}=-10, \mathrm{Y}=60, \mathrm{Z}=30$; MNI coords; Best Match at $0 \mathrm{~mm} ; 9.71 \mu \mathrm{V})$

According to table 3 and 4, they reveal bandwidth value of Piano Students and Karawitan Students when listening to Gendhing Lancaran. The bold number indicates the most dominant brainwave occurred during listening activity: delta for Piano Students and theta for Karawitan Students. Following, the 3D views and detailed location of those two dominant brainwave will be displayed.

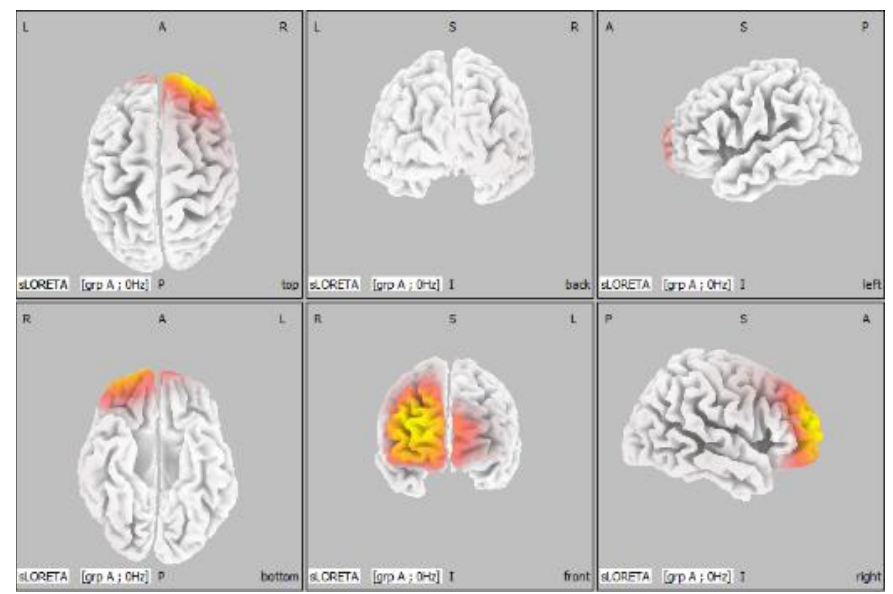

Fig. 3. Dominant brainwave of Piano students while listening to Gendhing Lancaran. The source generator of Delta brainwaves at Middle Frontal Gyrus - Frontal Lobe (Brodmann area 10; $\mathrm{X}=30, \mathrm{Y}=60, \mathrm{Z}=15$; MNI coords; Best Match at $5 \mathrm{~mm} ; 7.06 \mu \mathrm{V}$ )

According to figure 3 and 4, they reveal the dominant brainwave of Piano Students when listening to Piano Sonata is delta and located in Frontal Lobe while the dominant brainwave of Karawitan Student when listening to Gendhing Lancaran is theta and located in Temporal Lobe. 


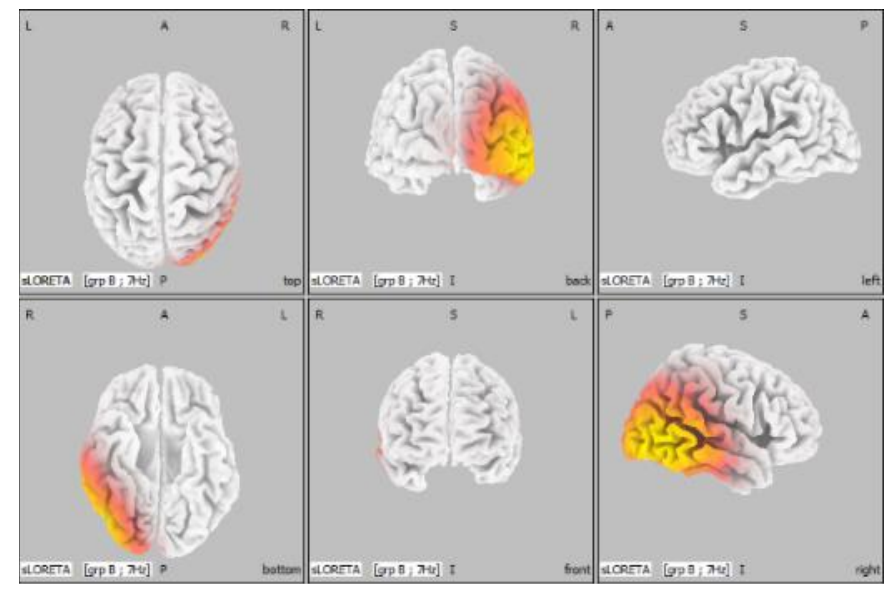

Fig. 4. Dominant brainwave of Karawitan students while listening to Gendhing Lancaran. The source generator of Theta brainwaves at Middle Temporal Gyrus - Temporal Lobe (Brodmann area 21; $\mathrm{X}=65, \mathrm{Y}=-55, \mathrm{Z}=0$; MNI coords; Best Match at $5 \mathrm{~mm} ; 7.62 \mu \mathrm{V}$ )

\section{DISCUSSION}

In both piano and Karawitan student, temporal lobe was the location where dominant brainwave occur when subjects listened to music familiar to them. Temporal lobe is the region of brain responsible for memory processing task. It could indicate that memory processing occurred when subjects were listening to familiar music. Similar things happened when subjects listened to particular music that is less familiar for them, in this case piano students listened to Gendhing Lancaran and Karawitan students listened to Piano Sonata, the dominant brainwave occurred in Frontal Lobe. In terms of brain activity, piano students achieved higher brain activity when listening to Piano Sonata compared to Karawitan students meanwhile Karawitan students achieved higher brain activity when listening to Gendhing Lancaran compared to piano students. This indicates a higher brain activity occurred when subject are more familiar with the particular music they listen to. When comparing brain activity of a subject listening to two particular music, piano student had higher brain activity when listening to piano sonata than Gendhing Lancaran as well as Karawitan student. Even though piano sonata is less familiar music for Karawitan student, their brain activity was higher when listening to this excerpts than Gendhing Lancaran as their more familiar music. An assumptions of this condition undergo to the characteristic of those two particular music. Musically, those two excerpts are different especially in tempo and melody succession. The allegro piano sonata presents a fast music with rapid melody succession. It is quite dissimilar with Gendhing Lancaran's tempo that is relative slow and calm while the melody of Gendhing Lancaran is a cyclical theme that is not as rapid as piano sonata. For researchers interested in this topic we suggest a future research by focusing in audio characteristic of the stimuli to provide a deeper elaboration of this result.

\section{ACKNOWLEDGMENT}

This research was partially supported by Indonesia Institute of the Arts Yogyakarta, Indonesia, and was partially supported by grant no. 611U109005 (2017) from Brain Science and Engineering Innovation Research Unit, Mae Fah Luang University and grant no. 02201A601814 (2017) from Mae Fah Luang University, Thailand. We thank all of the subjects involved in this research as main data provider of this studies.

\section{REFERENCES}

[1] V. Slumming, "Broca's Area Supports Enhanced Visuospatial Cognition in Ochestral Musicians". The Journal of Neuroscience, vol. 27(14), 2007.

[2] C. Gaser, and G. Schlaug, "Brain Structures Differ between Musicians and Non-Musicians". The Journal of Neuroscience, vol. 23(27), 2003.

[3] L. Patston, "The Effects of Background Music on Cognitive Performance in Musicians and Nonmusicians". Music Perception, 2011

[4] G. Schlaug, "The Brain of Musicians". In I. Peretz, \& R. J. Zatorre, The Cognitive Neuroscience of Music. New York: Oxford University Press, 2003

[5] I. Cross, "Music, Cognition, Culture, and Evolution". In I. Peretz, \& R. J. Zatorre, The Cognitive Neuroscience of Music. New York: Oxford University Press, 2003.

[6] S. Morrison and S. Demorest, "Cultural Constraints on Music Perception and Cognition”. Progress in Brain Research, Vol. 178, 2009.

[7] C. Stevens, "Music Perception and Cognition: A Review of Recent Cross-Cultural Research". Topics in Cognitive Science, 2012.

[8] A.T. Tierney, T.R. Bergeson, and D.B. Pisoni, "Effects of Early Musical Experience on Auditory Sequence Memory". Empirical Musicology Review, vol. 3(4), 2008.

[9] D.O. Bos, "EEG-based Emotion Recognition: The Influence of Visual and Auditory Stimuli", 2006.

[10] K. Tanji, "High-Frequency Gamma Band Activity in the Basal Temporal Cortex during Picture-Naming and Lexical-Decision Tasks". The Journal or Neuroscience, vol. 25(13), 2005.

[11] J.A. Grahn, and M. Brett, "Rhytm and Beat Perception in Motor Areas of the Brain". Jounal of Cognitive Neuroscience, vol. 19, 2007.

[12] R.C. Gur, "Sex Differences in Brain Gray and White Matter in Healthy Young Adults: Correlations with Cognitive Performance". The Journal of Neuroscience, vol. 19(10), 1999.

[13] R.D. Pascual-Marqui, "Standardized low-resolution brain electromagnetic tomograpgy (sLORETA): Technical Details, Methods Finding”. Exp. Clin. Pharmacol., vol. 24, pp. 5-12 (Suppl D), 2002. 